\title{
A REFORMA DO ENSINO PROFISSIONAL, DE FERNANDO DE AZEVEDO, NA ESCOLA NORMAL DE ARTES E OFÍCIOS WENCESLAU BRAZ
}

\section{The reform of the professional teaching, of Fernando de Azevedo,in the normal school of arts and ofícios Wenceslau Braz}

\section{Resumo}

Tereza Fachada Levy Cardoso ${ }^{1}$

Este artigo estabelece uma relação entre as mudanças promovidas na Escola Normal de Artes e Ofícios Wenceslau Braz, em decorrência da reforma do ensino técnico profissional da capital da república brasileira, durante os anos de 19271930, e as idéias que caracterizaram o movimento da Escola Nova. Os objetivos foram: avaliar se a reforma do ensino profissional promovida por Femando de Azevedo apresenta características do movimento da escola nova; examinar a importância dessas reformas para o ensino profissional e, por fim, identificar o impacto da reforma no âmbito da Escola Normal de Artes e Ofícios Wenceslau Braz, uma instituição escolar que, em sua organização e prática, mantinha-se dependente tanto do governo federal, quanto do govemo do Distrito Federal. A Escola Normal de Artes e Ofícios Wenceslau Braz, única escola normal que formou professores habilitados a lecionarem nas escolas de aprendizes e artífices, entre 1918 e 1937, foi criada pelo Decreto 1880, de 11 de agosto de 1917, no Distrito Federal, numa parceria entre o govemo da União e o da Prefeitura do Distrito Federal. Embora estivesse subordinada ao Ministério da Agricultura, Indústria e Comércio, foi em decorrência da Reforma Educacional ocomida durante a gestão de Femando de Azevedo (1894-1974), na direção da Instrução Pública do govemo do Distrito Federal, que se implantou o novo Regulamento do Ensino Profissional, em 1929, que vigorou até o fechamento da Escola e que atingiu também o ensino primánio e o normal. No livro NovosCaminhose novos fins encontram-se reunidos os pronunciamentos que Femando de Azevedo fez, justificando e explicando os princípios da reforma e que se constitui numa fonte de referência obrigatória para esta pesquisa, juntamente com o Regulamento implantado em 1929 na Escola Wenceslau Braz.

Palavras-chave: Escola nova; Políticas públicas; Aprendizado profissional; História da educação.

Professora e Doutora em História - CEFET/PR

E-mail: tereza@levycardoso.com.br 


\section{Abstract}

This work intends to establish a relationship among the changes promoted in the Normal School of Arts and Ofícios Wenceslau Braz, due to the reform of the professional technical teaching of the capital of the Brazilian republic, during the years of 1927-1930, and the ideas that characterized the movement of the New School. The objectives were: to evaluate the reform of the professional teaching promoted by Fernando de Azevedo presents characteristics of the movement of the new school; to examine the importance of the referred reforms for the professional teaching and finally, to identify the impact of that reform in the extent of the Normal School of Arts and Ofícios Wenceslau Braz, a school institution that, in it organization and practice, it stayed dependent so much of the federal government, as of the government from Federal district. The Normal School of Arts and Ofícios Wenceslau Braz, only normal school that it formed qualified teachers teach in the aprendizes schools and authors, between 1918 and 1937, it was created by the Ordinance 1880, of August 11, 1917, in Federal district, in a partnership between the government of the Union and the one of the City hall of Federal district. Although were subordinated to the Ministry of the Agriculture, Industry and Trade, it was due to Reforma that the new Regulation of the Professional Teaching happened during the administration of Fernando de Azevedo (18941974) in the direction of the govemment's from Federal district Public Instruction was implanted, in 1929, that it was in force until the closing of the School. In the book, Novos Caminhos e novos fins, they are gathered the pronouncements that Fernando de Azevedo did, justifying and explaining the beginnings of the reform and that it is constituted in a source of obligatory reference for this research, together with the Regulation implanted in 1929 in the Wenceslau Braz School.

Keywords: New school; Public politics; Professional teaching; History of education

\section{Introdução}

Este trabalho estabelece uma relação entre as mudanças promovidas na Escola Normal de Artes e Ofícios Wenceslau Braz, em decorrência da reforma do ensino técnico profissional da capital da república brasileira, durante os anos de 1927-1930, e as idéias que caracterizaram o movimento da Escola Nova.

Inicialmente foram abordadas as características do movimento da escola nova identificadas na reforma do ensino profissional efetivadas em 1928 por Fernando de Azevedo, diretor da Instrução pública no Distrito Federal, examinando-se em seguida a importância das referidas reformas para 0 ensino profissional e, por fim, avaliou-se o impacto dessa reforma no âmbito 
A reforma do ensino profissional, de Fernando de Azevedo, na Escola Normal de Artes e Ofícios ...

da Escola Normal de Artes e Ofícios Wenceslau Braz, uma instituição escolar que, em sua organização e prática, mantinha-se dependente tanto do governo federal, quanto do governo do Distrito Federal.

\section{Contextualizando a Reforma}

A Proclamação da República, em 1889, havia iniciado uma nova etapa da vida política brasileira e embora os grupos políticos dirigentes do país continuassem a privilegiar a agricultura como a atividade econômica mais importante, reconheceram a necessidade de diversificar as atividades econômicas e incrementar, mesmo timidamente, o nosso desenvolvimento industrial.

Em 1907, 33\% das indústrias encontravam-se no Rio de Janeiro, enquanto São Paulo participava com 16\% e o Rio Grande do Sul com 15\%. Predominavam as tecelagens, as refinações de açúcar, cervejarias e fundições. Formavam-se impérios industriais: grandes fazendeiros dirigiram-se para a atividade fabril, prósperos comerciantes começaram a participar de atividades industriais, mas a maioria dos capitães de indústria constituía-se de imigrantes que deviam sua fortuna inicial ao comércio, sobretudo de importação. Ao mesmo tempo, proliferavam manufaturas caseiras (PRADO JR, 1979).

Apesar de contar com o maior mercado urbano do país e da proximidade estratégica do governo federal, a indústria carioca, protagonista do primeiro surto industrial do século XIX, vai perdendo lentamente sua vantagem para São Paulo, que entra na década de $20 \mathrm{com} \mathrm{31,5 \%} \mathrm{do} \mathrm{total} \mathrm{da} \mathrm{produção}$ industrial brasileira, contra $21 \%$ do Rio de Janeiro. Entre vários motivos, porque São Paulo modernizou mais sua indústria e também exportou mais que 0 restante do país. Entretanto, o Distrito Federal se manteve, durante toda a Primeira República, na posição de segundo pólo industrial (CANO, 1983).

Acompanhando esse processo, a partir do final do século XIX, a grande indústria substituiu, aos poucos, os artesãos pelos operários, cujas condições de vida e de trabalho estavam bem abaixo das do artífice independente. Com a grande indústria foi introduzida também a mecanização em larga escala, levando à depressão dos salários e à incorporação maciça de mulheres e crianças no trabalho fabril.

A questão do trabalho e da formação profissional precisou ser enfrentada pelos primeiros governos da República brasileira, pela necessidade de formação de uma mão-de-obra com certa qualificação, o que justificava a implantação de escolas federais de formação técnica. Isso significa que a conjuntura histórica no Brasil da República Velha favorecia a expansão do ensino profissional. Assim, foi no início do século XX que detectamos o surgimento, no Brasil, de políticas públicas favoráveis ao ensino técnico-profissional. 
Como assinalou Luiz Antonio Cunha, o ensino profissional poderia atender às aspirações de duas correntes distintas: para a ideologia conservadora, seria um instrumento de controle social, protegendo a sociedade contra a desordem, ocupando e "civilizando" os desocupados e ociosos, os "desfavorecidos da fortuna". Para a ideologia progressista, industrialista, propiciaria o "desenvolvimento de forças produtivas", além de propagar os valores atribuídos à indústria tais como "progresso, emancipação econômica, independência política, democracia e civilização" (CUNHA, 2000).

Dessa forma o mundo do trabalho entrava no campo da educação formal, por um lado, por meio da capacitação de trabalhadores que produzissem "de acordo com as máquinas", exigência da Revolução Industrial, ou mesmo de renovação do aprendizado artesanal, que precisava de "especializações modernas" e, por outro lado, por meio do movimento pedagógico de renovação da educação intitulado de Escola Nova, que fundamentava a ação pedagógica na ação e na atividade da criança.

Ou seja, a instrução técnico-profissional promovida pelas indústrias ou pelos Estados e a educação ativa das escolas novas, embora por caminhos diferentes, baseavam-se num mesmo elemento formativo, o trabalho, e visavam ao mesmo objetivo formativo, o homem capaz de produzir ativamente (MANACORDA, 2000).

Assim, a relação que se estabelece entre educação, sociedade e tecnologia passa a incluir o mundo do trabalho na escola. Apesar de predominar ainda de forma geral na Europa e também no Brasil do século XIX a escola "livresca", iniciou-se, no entanto, um movimento de ampliação da educação escolar, paralelo ao progresso industrial e ao desenvolvimento da nova aprendizagem profissional.

Entretanto, o movimento das reformas da instrução pública, ao longo da Primeira República, demonstrou a liderança que o grupo paulista detinha na condução da política nacional. Esta liderança serviu-se de várias estratégias, como, por exemplo, a repercussão alcançada em outros estados do país pelo modelo de reforma educacional implementada no Estado de São Paulo, em 1920, que se relacionava com um projeto político de alcance nacional .

Nos anos 20, Fernando de Azevedo (1894-1974) fazia parte do grupo de intelectuais e educadores que desejavam reformas na Educação brasileira, integradas, por sua vez, no projeto liberal de reconstruir a sociedade por meio da educação, onde se destacava a função social da escola.

Assim, a educação deveria ser um serviço essencialmente público e entre outras características, leiga, integral, "igual para todos, organizada em regime de vida e trabalho em comum, própria para desenvolver a consciência social de igualdade, solidariedade e cooperação, e a consciência econômica do trabalho produtivo", tendendo à obrigatoriedade até 18 anos e gratuito sempre (AZEVEDO, p. 19). 
Quanto à educação técnico-profissional, deveria se estender aos níveis secundário e superior, com base na economia nacional, e que fosse capaz de formar técnicos e operários em diferentes graus hierárquicos de uma indústria.

É oportuno lembrar que o paradigma que dominava a educação técnico-científica brasileira nesse período refletia o método de trabalho mais em voga no setor industrial mundial, o chamado taylorismo, já incorporando as inovações trazidas por outro modelo, que o complementa e que desponta a partir dos anos 10, o fordismo. Isso significa que ao dividir as tarefas entre os operários, o taylorismo retirou dos trabalhadores a necessidade de pensar, eliminando, assim, a criatividade e conseqüentemente a satisfação no trabalho.

O objetivo era tornar o trabalhador mais produtivo, evitando a exploração de suas forças físicas e mentais até os limites de sua resistência fisiológica, como acontecia até então. Todavia, Taylor não criou um modo de se trabalhar melhor, mas sim de se produzir mais.

Fernando de Azevedo, ao contrário, pensava uma escola que não separava a educação profissional da formação geral do homem, como ele mesmo registrou:

"Eu tenho da vida, e, portanto, da educação, uma concepção integral, que não me permite considerar o homem apenas como "instrumento de trabalho"; que me criou a consciência da necessidade de aproveitar, na educação, todas as forças ideais, isto é, tudo aquilo que dá sentido e valor à vida humana, e, que, portanto, me obriga a reivindicar para o indivíduo os seus direitos em face da sociedade, à qual aliás ele tanto mais se adaptará e servirá, como unidade eficiente, quanto mais desenvolver e aperfeiçoar sua personalidade, em todos os sentidos" (p.19).

De acordo com Fonseca (1986, p. 269), a reforma Fernando de Azevedo iniciou uma nova fase da filosofia educacional brasileira, porque rompeu "com os fins individualistas da escola antiga, e colocou em primeiro plano as preocupações de ordem social".

\section{0 que foi a Reforma}

Em 1927, Fernando de Azevedo aceitou o convite para assumir o cargo de diretor da Instrução Pública do governo do Distrito Federal, onde permaneceu até a Revolução de 1930, que mudou os rumos da política, determinando a deposição do Presidente Washington Luís. Em 1932, ele foi signatário do Manifesto dos Pioneiros da Escola Nova, um marco na história da educação brasileira (PILETTI, 2002). 
Durante a sua gestão na direção da Instrução Pública ocorreu uma reforma educacional consubstanciada no Decreto 3281, de 23 de janeiro de 1928, que atingiu, além do ensino técnico profissional, também o ensino primário e o normal. Essa reforma, segundo o próprio Fernando de Azevedo, foi inspirada pelas teorias de E. Durkheim, na França, de Kerschensteiner, na Alemanha, e, sobretudo, de J. Dewey, na América do Norte e pretendia alterar profundamente a sociedade brasileira:

A reforma da educação, com que se instituiu a escola para todos (escola única), organizada à maneira de uma comunidade e baseada no exercício normal do trabalho em cooperação, implantou no Brasil escolas novas para uma nova civilização. (...) quis o Estado preparar as gerações não para a vida, segundo uma representação abstrata, mas para a vida social do seu tempo, sob um regime igualitário e democrático em evolução, transmudando a escola popular não apenas num instrumento de adaptação (socialização), mas num aparelho dinâmico de transformação social. Para este fim, a reforma articulou a escola com o meio social, modificou a sua estrutura, remodelando-a num regime de trabalho e de vida em comum, sob a feição de uma comunidade em miniatura, em que seria utilizadas as diversas formas de atividade social, que desenvolvem o sentimento de responsabilidade e de cooperação" (p. 17).

A implantação de uma política pública em educação com o caráter revolucionário que a caracterizava naquela conjuntura provocou, como era de se esperar, resistências e oposição. Embora não seja objetivo deste estudo trabalhar essa questão, deve-se ressaltar que, de acordo com Fernando de Azevedo, os professores e pais de alunos, de maneira geral, apoiaram a reforma, enquanto os políticos locais tentavam impedi-la. Entretanto, de acordo com Xavier e Freire (2002): “O movimento das reformas da instrução pública ocorrido nos estados brasileiros ao longo da Primeira República expressa com clareza a liderança exercida pelo grupo paulista na condução da política nacional". Esses autores analisaram os desdobramentos políticos que o modelo de reforma educacional implementado no Estado de São Paulo, em 1920 e depois exportado para o Distrito Federal, em 1927, provocaram no âmbito da educação.

Logo que assumiu o cargo de Diretor da Instrução Pública do Distrito Federal, Fernando de Azevedo anunciou as duas grandes linhas de ação que deveriam orientar o seu projeto de reforma: a necessidade de reformulação da legislação vigente, tarefa precedida pela realização de um censo escolar e a convocação de sua equipe, paralelamente à montagem do esquema de apoio e divulgação da reforma em órgãos da imprensa e instituições civis, como a Associação Brasileira de Educação (XAVIER; FREIRE, 2002). 
A proposta de Fernando de Azevedo era partir do ponto zero, ou seja, ele procurou convencer a opinião pública da validade e necessidade de seu projeto de reforma, reforçando "a idéia de que a situação caótica da instrução pública do Distrito Federal era resultado da ação clientelística e estreita dos políticos que tratavam a instrução como um bem privado e não no interesse público". Como estratégia, recorreu aos argumentos técnicos e especializados, característicos do discurso dos reformadores do final da década de 20, para justificar as medidas determinadas pelos planos de reforma da instrução pública. No entanto, o que se visava era submeter as lideranças locais "aos argumentos técnicos e à inspiração política que a fundamentavam, qual seja, o modelo paulista de reforma do ensino inserido no projeto de reconstrução política da nação segundo os ideais de República partilhados por suas principais lideranças" (XAVIER; FREIRE, 2002).

\section{A Implementação da Reforma}

A finalidade dada ao ensino profissional nas primeiras décadas do século XX encontra-se resumida no Regulamento Rivadávia Correia, de 1916, onde se lê em seu artigo 1ํ "O ensino profissional, mantido pela Prefeitura, tem por fim dar a pessoas de ambos os sexos a instrução técnica necessária para o exercício de profissão em que possam com facilidade encontrar trabalho remunerado".

O decreto 3281, que efetiva a reforma do ensino técnico-profissional no Distrito Federal, em 23 de janeiro de 1928, mantém a preocupação da legislação anterior de fornecer instrução técnica para o exercício de uma profissão. No entanto, inclui as idéias de pesquisa e ação, necessários como instrumentos de renovação social, como se lê no Artigo 310: "O ensino teórico terá sempre em vista ministrar conhecimentos de imediata aplicação industrial, sendo para isso intimamente relacionado aos trabalhos de laboratórios e às excursões".

Fonseca (1986) observou que a reforma foi profunda, "pela interpretação elevada que dava às suas finalidades", que encontram-se em outro artigo, o 141:

O ensino técnico-profissional terá por fim:

a) ministrar o conhecimento e a prática de um ofício;

b) elevar o nível moral e intelectual do operário;

c) despertar e desenvolver-lhe a consciência de suas responsabilidades, como a consciência das bases científicas e da significação social de sua arte;

d) alargar-lhe a visão técnica e artística; 
e) aperfeiçoar-lhe a técnica no sentido do maior rendimento do trabalho;

f) transformá-lo, por esta maneira, num elemento de progresso técnico nas oficinas e nas indústrias nacionais.

Ou seja, a nova diretriz que a reforma imprimia ao ensino técnicoprofissional coadunava-se com as idéias da escola nova defendidas por Fernando de Azevedo, onde o Estado devia preparar as gerações "para a vida social do seu tempo", e onde a escola popular não se restringia a promover a socialização, mas se configurava num "aparelho dinâmico de transformação social", articulando a escola com a sociedade, congregando para o mesmo fim "a escola e a família, pais e professores", além de criar outros mecanismos de integração entre essas partes, como por exemplo os círculos de pais e professores, ou os conselhos escolares, rompendo, de várias formas, "as barreiras que se opunham à interpenetração da escola e da sociedade", para que ela pudesse exercer uma "ação contínua, intensa e penetrante sobre todas as camadas e instituições sociais" (AZEVEDO, [199?]).

Mas de que modo essas diretrizes foram aplicadas no ensino técnicoprofissional?

Em 22 de novembro de 1928 era expedido o decreto municipal 2940, regulamentando o ensino que havia sido reformado por Fernando de Azevedo. Uma das dominantes daquela reforma era a articulação entre as várias espécies de ensino ministradas pela Prefeitura, o que ficaria esclarecido pelo artigo 274, do decreto citado: (FONSECA, 1986, p. 173)

As escolas profissionais se organizarão com uma norma de vida em comum, sobre uma base de autogovemo, atividade produtiva e cooperação social.

§único - A escola profissional (escola de trabalho profissional) e a escola primária (escola de trabalho educativo) em que se apóia e com que se articula, mediante os cursos complementares anexos, deverão manter e desenvolver a sua solidariedade orgânica:

a) pela orientação do último ano do curso primário, no sentido vocacional (curso pré-vocacional) com predominância de trabalhos manuais e desenho;

b) pela feição marcadamente vocacional dos cursos complementares, que funcionando obrigatoriamente nos próprios estabelecimentos de ensino profissional a que estão anexos, serão dados por professores primários do quadro, designados em comissão;

c) pela orientação dos seus programas ou planos de estudo projetados e realizados sempre em vista dessa interdependência;

d) pelo desenvolvimento, na escola primária, dos testes de escolaridade e orientação profissional; 
e) por meio de reuniões periódicas de inspetores escolares e diretores de escolas e institutos profissionais, sob a presidência do SubDiretor Técnico, para o exame e concerto de medidas tendentes a desenvolver na escola primária o interesse pela educação técnica-profissional;

f) por visitas freqüentes de alunos de escola primária às oficinas em atividade e às exposições permanentes das escolas e institutos profissionais.

Então na fase de implantação da reforma, o ensino profissional articulava-se e apoiava-se no ensino primário, por meio de cursos complementares vocacionais. A articulação do ensino técnico-profissional com a escola secundária na capital do país só se estabeleceu anos mais tarde, pelo Decreto 3763, de 1. o de fevereiro de 1932 .

Outra novidade introduzida no ensino municipal também pelo decreto 2940 que regulamentou a Reforma Fernando de Azevedo foi a criação dos Conselhos Escolares, previstos no seu artigo 350, que buscava um contato direto com o mundo da produção, quando industriais, por exemplo, eram chamados a integrar os conselhos que se organizariam em cada escola e instituto profissional e eram presididos pelo Diretor Geral de Instrução Pública. Dele faziam parte: "o diretor da escola, um representante da indústria e um do comércio da especialidade para a qual a escola se organizou, um professor, um mestre ou contra-mestre e, conforme a natureza das atividades do estabelecimento, um artista representante da escola, centro ou círculo de belas-artes".

No âmbito da política estadual, e como desdobramento da nova política educacional surgia, em 14 de janeiro de 1929, pelo decreto 2380, o Regulamento do Ensino Profissional, que trazia uniformidade às normas das escolas profissionais do Estado do Rio de Janeiro. (FONSECA, 1986, p. 209-211)

\section{0 que muda na Escola Normal de Artes e Ofícios Wenceslau Braz}

A Escola Normal de Artes e Ofícios Wenceslau Braz, única escola normal que formou professores habilitados a lecionarem nas escolas de aprendizes e artífices, entre 1918 e 1937, foi criada pelo Decreto 1880, de 11 de agosto de 1917, no Distrito Federal, numa parceria entre o governo da União e o da Prefeitura do Distrito Federal. Em 1919 a sua gestão foi transferida inteiramente para o governo federal, que a manteve até 11 de junho de 1937, quando a Escola foi fechada e demolida, para dar lugar a um novo tipo de estabelecimento de ensino profissional: a Escola Técnica Nacional (CARDOSO, 2000). 
A necessidade de uma escola normal voltada para formar professores para as escolas técnicas já era reconhecida desde o fim do século XIX, quando Rui Barbosa apresentou, em 13 de abril de 1882, à Câmara dos Deputados, um projeto para a criação de uma Escola Normal Nacional de Arte Aplicada, idéia que não foi adiante.

Para qualificar profissionais que atendessem a essa expansão do ensino profissional é que foi criada a Escola Normal de Artes e Ofícios Wenceslau Braz, como o ponto de partida para solucionar o grave problema da falta de professores formados especificamente para atuarem nas escolas técnicas, tarefa por um lado suprida por mestres de ofícios provenientes das fábricas e das oficinas, que não tinham o conhecimento suficiente para atender aos requisitos de base teórica, e por outro lado pelos professores do ensino primário, recrutados na rede pública, aos quais faltavam as habilitações demandadas pelos cursos oferecidos.

A Escola Normal de Artes e Ofícios Wenceslau Braz iniciou suas atividades oferecendo basicamente dois cursos: o Curso Técnico Profissional, freqüentado por alunos e o Curso de Trabalhos Manuais, predominantemente formado por alunas. Foi, portanto, uma escola mista desde a sua fundação, mas é relevante registrar que sempre houve um maior número de alunas, durante todo o período de seu funcionamento.

Embora a Escola Normal de Artes e Ofícios Wenceslau Braz estivesse subordinada ao Ministério da Agricultura, Indústria e Comércio, foi em decorrência da Reforma Fernando de Azevedo que se elaborou e implantou o novo Regulamento do Ensino Técnico-Profissional, em 1929. Aliás, foi em decorrência da reforma que o curso normal foi separado, passando a ser ministrado paralelamente aos demais cursos profissionais.

$\mathrm{O}$ autor do regulamento foi o diretor da Wenceslau Braz, Carlos Américo Barbosa de Oliveira que o concluiu em dezembro de 1929, "para que a Diretoria Geral de Indústria e Comércio - a qual estão subordinadas as escolas de Aprendizes e Artífices", pudesse se manifestar sobre o assunto antes do final daquele ano. Seguindo as "exigências primordiais da pedagogia moderna", vigorou até o fechamento da Escola, em 1937.

A introdução do documento inicia-se com o diretor constatando que não se questionava mais a importância do ensino profissional como elemento educativo, ao contrário, era mesmo aconselhada a sua generalização. Em seguida registra a importância "de todos os pedagogos, que incluíram na escola nova o "manual training" como disciplina e recomendaram a criação de escola técnicas elementares para formar os verdadeiros profissionais".

Depois justifica a necessidade de se fazer este novo Regulamento, uma vez que a Escola ainda estava submetida ao Regulamento Municipal (o Rivadávia Correia, de 1916), que remontava à época de sua criação e transfe- 
rência para o governo federal, em 1919, havendo então a necessidade de lhe dar uma nova organização, seguindo a direção geral da educação profissional a cargo do Ministério da Agricultura, Indústria e Comércio.

Entretanto, o citado Regulamento do Ensino Profissional não se restringia à Escola Normal Wenceslau Braz, mas aplicava-se a todas as Escolas de Aprendizes Artífices e a cursos técnicos subvencionados, conforme o capítulo I, artigo 1 .

A direção geral desse ensino ficaria a cargo da Inspetoria, que além do Inspetor Geral, compunha-se de mais quatro inspetores regionais, além de outros funcionários auxiliares, baseados na Escola Normal Wenceslau Braz.

O capítulo II, que trata da Escola Normal de Artes e Ofícios Wenceslau Braz, estabelece que a mesma tem por fim: preparar professores para estabelecimentos de ensino profissional - o curso normal; e mestres para estes estabelecimentos e para a indústria em geral - formando mão-de-obra qualificada para o mercado de trabalho.

Inicialmente foram oferecidos 7 cursos profissionais, que eram ministrados para atender às seguintes necessidades: trabalhos de madeira; de metal; de mecânica e eletricidade; de economia doméstica; de modas; de artes decorativas; de técnico de férias, que eram ministrados paralelamente ao curso normal. Este último, de técnico de férias, ministrado de forma prática nas oficinas, destinava-se especialmente aos alunos do sexo masculino das escolas secundárias.

O regulamento previu ainda um curso complementar também só para o sexo masculino, para o preparo de alunos vindos das escolas de aprendizes artífices e de outros estabelecimentos, como as escolas primárias, e que se destinava a servir de escola de aplicação ao curso normal. Com duração de um ano, dividia-se em duas partes: uma com maior ênfase na parte teórica, para os que vinham das escolas de aprendizes artífices e outra com ênfase em práticas de oficina, para aqueles alunos vindos da escola primária.

O regulamento tratava ainda da organização da congregação, constituída pelos professores e adjuntos, da administração em geral da Escola, que incluía os cuidados sanitários da mesma a cargo do médico escolar, além do regime escolar relativo às condições de ingresso, exames de admissão, gratificações para o corpo docente, regime disciplinar, etc.

No capítulo III, relativo às escolas de Aprendizes Artífices, o artigo 92 informa que o governo federal manterá, em cada um dos estados da República, Escolas de Aprendizes Artífices destinadas a ministrar gratuitamente o ensino primário vocacional e o ensino profissional elementar, por intermédio do Ministério da Agricultura, Indústria e Comércio. A duração seria de dois anos.

As Escolas de Aprendizes Artífices formavam operários e contra-mestres em aulas teóricas e práticas, o que foi realmente um avanço para a época, 
uma vez que esses profissionais comumente se preparavam vendo outros profissionais trabalhando, no dia-a-dia prático, sem qualquer teoria que lhes fundamentasse a prática.

As 38 páginas do Regulamento do Ensino Técnico-Profissional indicam uma mudança para este tipo de ensino, uma vez que pretendia melhorar o nível moral e intelectual do operário, ao unir teoria e prática e inserir um profissional muito mais bem formado não apenas no mercado de trabalho, mas também na vida social.

No caso da Escola Normal, houve a preocupação de inseri-la no universo técnico formador de mão-de-obra, para onde estavam voltados os seus cursos. Entre as oficinas, podemos citar a de marcenaria, de lataria, oficina de flores, de chapéus, bordados e costura, que fabricavam produtos que eram vendidos, acarretando uma renda para a Instituição e expostos em Feiras de Amostras realizadas na própria Escola. O trabalho das oficinas produziu muitos artigos que a escola deixou de adquirir, além de gerar renda. A exceção foi apenas o curso comercial, aliás muito procurado por alunos de ambos os sexos.

Quando se analisa a documentação produzida pela administração da Escola, como por exemplo, relatórios oficiais enviados pela direção ao Ministério por ela responsável, no período até 1930, percebe-se que havia uma política de garantir a colocação dos egressos dos cursos da Escola no mercado de trabalho, de valorizar a participação feminina e de priorizar, mas não limitar, os cursos oferecidos à demanda do mundo industrial.

A partir dos anos 30 e da Revolução que colocou no poder novos personagens da cena política brasileira, o ensino profissional técnico passa a merecer uma atenção maior. Com a reorganização administrativa do Estado brasileiro e a extinção do Ministério da Agricultura, Indústria e Comércio passou a vincular-se ao recém-criado Ministério da Educação e Saúde Pública, o que significou também um novo espaço político-social, agora ao lado da Educação, embora no interior da estrutura do novo Ministério ainda persistisse a separação entre "ensino técnico profissional" e "ensino" em geral.

A industrialização brasileira deslanchada durante a Era Vargas inseria-se num modelo econômico capitalista, de forte apelo nacionalista, interessado em incorporar setores populares, de maneira controlada, para ampliar o seu mercado de consumo, o que exigia trabalhadores à altura do desafio de transformar o Brasil num país moderno.

A educação profissional passa a ser necessária para o projeto traçado pelo capital industrial. Para atender tais objetivos é que a formação e a qualificação da mão-de-obra brasileira, especialmente aquela ligada às atividades industriais, mais uma vez precisa ser reavaliada. Como a Escola Normal de Artes e Ofícios Wenceslau Braz, nos moldes em que vinha operando, não atendia satisfatoriamente a essas novas expectativas, o governo federal con- 
cluiu pelo seu fechamento, em 1937. Derrubado o seu prédio, construíram no mesmo local a Escola Técnica Nacional, dentro da filosofia de formar artífices, mestres e técnicos para a indústria nacional, e não mais para atender às necessidades de escolas primárias do município, ou preparar docentes e pessoal administrativo voltado para o ensino industrial.

\section{Conclusão}

Foi em decorrência das idéias que caracterizaram o movimento da Escola Nova que ocorreu a reforma do ensino técnico profissional na capital da república brasileira, efetivada em 1928, por Fernando de Azevedo, diretor da Instrução Pública no Distrito Federal durante os anos de 1927-1930.

A elaboração e implantação do novo Regulamento do Ensino Técnico-Profissional, em 1929, em conseqüência da reforma Fernando de Azevedo, atingiu a Escola Normal de Artes e Ofícios Wenceslau Braz, bem como todas as Escolas de Aprendizes Artífices e cursos técnicos subvencionados. A mudança mais visível que provocou foi conceber um novo tipo de trabalhador, que deveria ser formado unindo-se a teoria e a prática, que estivesse apto a ingressar como mão-de-obra qualificada no mercado de trabalho, notadamente o industrial, mas que fosse consciente do seu papel social. A idéia de uma integração escola-comunidade, por meio dos conselhos das Comunidades, facilitaria essa tarefa de levar adiante um diálogo entre a escola e a sociedade na qual estava inserida. E isto era, sem dúvida, uma novidade.

Se por um lado a Escola Normal de Artes e Ofícios Wenceslau Braz ganhou maior importância política por sediar a direção geral do Ensino Profissional, por outro lado continuou sendo o único estabelecimento nacional a preparar professores para estabelecimentos de ensino profissional, sinalizando os limites do discurso progressista.

\section{Referências}

AZEVEDO , F. Novos caminhos e novos fins: a nova política de educação no Brasil. São Paulo, SP: Melhoramentos, [199?].

CANO, W. Raízes da concentração industrial em São Paulo. São Paulo, SP: Queiroz, 1983.

CARDOSO, T. F. L. A Formação Docente na Escola Normal de Artes e Ofícios Wenceslau Braz (1917-1937). In: Congresso Brasileiro de História da Educação,1. Anais... Rio de Janeiro, RJ: SBHE, 2000. 
CUNHA, L A. C. R. O ensino industrial-manufatureiro no Brasil. In: Revista Brasileira de Educação, n. 14, p. 89 a 107, maio/ago. 2000.

FONSECA, C. S. da. História do ensino industrial no Brasil. Rio de Janeiro, RJ: SENAI/DN/DPEA, v. 5, 1986.

MANACORDA, M. A. História da educação. São Paulo, SP: Cortez, 2000.

PRADO JR, C. História econômica do Brasil. São Paulo, SP: Brasiliense, 1976.

XAVIER, L N. e FREIRE, A. Educação e política na reforma da instrução pública do Distrito Federal (1927-1930). In: Congresso Brasileiro de História da Educação, 2. Anais... Natal: SBHE, 2002.

Recebido em: 27/08/2004

Aprovado em: 30/11/2004 